\title{
Vida útil pós-colheita de bananas 'Prata' armazenadas sob refrigeração
}

\author{
Post-harvest usefull life of 'Prata' bananas stored under refrigeration \\ Vida útil poscosecha de los plátanos 'Plata' almacenados en refrigeración
}

\section{Resumo}

A banana é um fruto climatérico, necessitando portanto, de armazenamento refrigerado adequado. Objetivou-se avaliar a vida útil pós-colheita de bananas 'Prata' armazenadas sob refrigeração. Os frutos foram armazenados em câmara fria, durante 15 dias a $13 \pm 4{ }^{\circ} \mathrm{C}\left(85 \pm 4 \%\right.$ U.R.) seguido de 8 dias a $22 \pm 4{ }^{\circ} \mathrm{C}$ ( $85 \pm 4 \%$ U.R.). Utilizou-se o delineamento inteiramente casualizado em esquema fatorial 3 x 8 , sendo o primeiro fator (Prata Anã, Prata Catarina e Prata Rio) e o segundo os tempos $(0,5,10,15,17,19,21$ e 23) dias. A cada tempo analisadas: perda de massa, cor da casca, aparência externa, firmeza da polpa, espessura da casca, diâmetro da polpa, pH, acidez titulável, sólidos solúveis, relação SS/AT e açúcares solúveis totais. Utilizou-se estatística descritiva, aplicando média e desvio padrão proveniente de 3 repetições de 3 frutos por parcela. Os frutos do genótipo Prata Catarina apresentaram menor perda de massa e melhor aparência externa no $21^{\circ}$ dia de armazenamento. Os genótipos Prata Anã e Prata Rio apresentaram metabolismo mais lento e acelerado, respectivamente, a $13{ }^{\circ} \mathrm{C}$, demonstraram comportamento fisiológico diferenciado quanto a cor da casca, firmeza da polpa, acidez titulável, sólidos solúveis e açúcares solúveis totais. Baseado na aparência externa, a vida útil pós-colheita dos frutos dos genótipos Prata Anã e Prata Rio foi de 19 dias (15 dias a 13 ${ }^{\circ} \mathrm{C}$ e 4 dias a $\left.22^{\circ} \mathrm{C}\right)$, do genótipo Prata Catarina foi de 21 dias $\left(15\right.$ dias a $13{ }^{\circ} \mathrm{C}$ e 6 dias a $\left.22^{\circ} \mathrm{C}\right)$.

Palavras-chave: Genótipos; Musa spp.; Qualidade.

\section{Abstract}

Banana is climacteric fruit and therefore needs adequate refrigerated storage. Aimed evaluate the post-harvest useful life of 'Prata' bananas stored under refrigeration. The fruits were stored in a cold chamber, during 15 days at $13 \pm 4{ }^{\circ} \mathrm{C}$ ( $85 \pm 4 \%$ U.R.) followed by 8 days at $22 \pm 4{ }^{\circ} \mathrm{C}$ ( $85 \pm 4 \%$ U.R.). A completely randomized design was used in a $3 \times 8$ factorial scheme, the first factor being (Prata Anã, Prata Catarina and Prata Rio) and the second the times $(0,5,10,15$, 17, 19, 21 and 23) days. At each time analized: mass loss, skin color, external appearance, pulp firmness, skin thickness, pulp diameter, $\mathrm{pH}$, titratable acidity (TA), soluble solids (SS), soluble solids and titratable acidity ratio SS / 
TA, and total soluble sugars were analyzed. Descriptive statistic were used by applying the mean and standard deviation from tree replication of tree fruits per plot. The fruits of the Prata Catarina genotype showed less weight loss and better external appearance on the 21st day of storage. The Prara Anã and Prata Catarina genotypes showed slower and more accelerated metabolism, respectively at $13^{\circ} \mathrm{C}$, as they showed different physiological behavior in terms of skin color, pulp firmness, titratable acidity, soluble solids and total soluble sugars. Based on the external appearance, the post-harvest useful life of the fruits of the Prata Anã and Prata Rio genotypes was 19 days $\left(15\right.$ days at $13{ }^{\circ} \mathrm{C}$ and 4 days at $22^{\circ} \mathrm{C}$ ), while that of the fruits of the Prata Catarina genotype was 21 days $\left(15\right.$ days at $13{ }^{\circ} \mathrm{C}$ and 6 days at 22 $\left.{ }^{\circ} \mathrm{C}\right)$.

Keywords: Genotypes; Musa spp.; Quality.

\section{Resumen}

El plátano es una fruta climatérica y por lo tanto, necesita un almacenamiento refrigerado adecuado. El propósito fue evaluar la vida útil pos cosecha de los plátanos 'Plata' almacenados en refrigeración. Los frutos se almacenaron en cámara fría, durante 15 días a $13 \pm 4{ }^{\circ} \mathrm{C}$ ( $85 \pm 4 \%$ U.R.) seguido de 8 días a $22 \pm 4{ }^{\circ} \mathrm{C}$ ( $85 \pm 4 \%$ U.R.). Se utilizó un diseño completamente al azar en un esquema factorial de 3 x 8 , siendo el primer factor (Plata enana, Plata Catarina y Plata Rio) y el segundo los tiempos $(0,5,10,15,17,19,21$ y 23) días. En cada tiempo analizados: pérdida de masa, color de la piel, apariencia externa, firmeza de la pulpa, grosor de la piel, diámetro de la pulpa, pH, acidez titulable, sólidos solubles, sólidos solubles y relación de acidez titulable SS / AT y azúcares solubles totales. Se utilizó estadística descriptiva aplicando la media y la devación estándar de tres repticiones de tres frutos por parcela. Los frutos del genotipo Plata Catarina mostraron menor pérdida de peso y mejor aspecto externo a los 21 días de almacenamiento. Los genotipos Plata enana y Plata Rio mostraron un metabolismo más lento y más acelerado, respectivamente a $13{ }^{\circ} \mathrm{C}$, ya que mostraron un comportamiento fisiológico diferente en términos de color de piel, firmeza de la pulpa, acidez titulable, sólidos solubles y azúcares solubles totales. En función del aspecto externo, la vida útil pos cosecha de los frutos de los genotipos Plata enana y Plata Rio fueron 19 días (15 días a $13^{\circ} \mathrm{C}$ y 4 días a $22{ }^{\circ} \mathrm{C}$ ), mientras que la de los frutos del genotipo Plata Catarina fueron 21 días (15 días a $13{ }^{\circ} \mathrm{C}$ y 6 días a $22^{\circ} \mathrm{C}$ ).

Palabras clave: Genótipos; Musa spp.; Calidad.

\section{Introdução}

O Brasil é o terceiro produtor mundial de frutas com uma produção superior a 40 milhões de toneladas, isso pode ser explicado pelo extenso território do país, localização geográfica, solo e clima favoráveis (Rosa et al., 2017; Santos et al., 2018). A produção de banana com 6.812 .708 toneladas, inclusive, no Nordeste do Brasil, se destaca com produção de 2.332.671 toneladas (IBGE, 2019a; IBGE, 2019b). Os investimentos na área da bananicultura favorecem as tecnologias aplicadas na produção da banana proporcionando maior qualidade e volume de produção (Sousa; Alencar; Alencar, 2017).

No Ceará, a Chapada do Apodi tem se destacado nas últimas décadas pelo desenvolvimento da fruticultura e pela expansão de mercado. Nesse espaço, a banana é produzida, praticamente, em todos os perímetros irrigados e é destinada ao mercado externo e regional (EMBRAPA, 2014), sendo a variedade mais produtiva a 'Prata Anã', sobretudo o genótipo 'Prata Catarina', seguida pela 'Prata Rio' (EMBRAPA, 2017).

O município de Limoeiro do Norte, segundo o IBGE (2015), se encontra em segundo lugar em área colhida, quantidade produzida e rendimento médio com valores de 2.100 ha, 41.160 e 19,60 $\mathrm{T} \mathrm{ha}^{-1}$, respectivamente.

Em relação à 'Prata Anã', a 'Prata Catarina' apresenta diversas vantagens comparativas, tais como cachos e frutos maiores, maior percentual de cachos comerciais na primeira safra, melhor coloração de casca, casca mais limpa e maior tolerância ao Mal do Panamá (Lichtemberg; Hinz, 2010). O sabor da polpa se assemelha ao da 'Prata Anã', largamente aceita no mercado nacional. Vale salientar que a produtividade da 'Prata Catarina' é 20\% maior do que a cultivar citada anteriormente (Lichtemberg; Hinz, 2010). Dessa forma, o uso alternativo de novas cultivares pressupõem que essas apresentem qualidade próxima à 'Prata Anã' para aceitação do público e da cadeia produtiva (Pimentel et al., 2010).

A banana é uma cultura bastante sensível às diferentes condições edafoclimáticas e possui um ciclo produtivo precoce se comparada a outros cultivos frutíferos, e um dos grandes problemas enfrentados pelos produtores é a obtenção de cultivares produtivas, resistentes às principais doenças e que sejam adaptadas aos diferentes ecossistemas brasileiros, por isso é importante avaliar o desempenho agronômico das cultivares obtidas pelos programas de melhoramento genético e que são 
lançadas no mercado, bem como sua produção e o comportamento fisiológico destas cultivares para desta forma, disponibilizar maior número de informações aos produtores, procurando, assim, incentivar a adoção destas novas cultivares, com o objetivo de elevar a produtividade (Fernandes, 2012; Maia; Sousa; Sousa 2019).

A banana é um fruto climatérico, possuindo curto período de amadurecimento, e consequente menor tempo de armazenamento sob temperatura ambiente (Araújo et al. 2020). Segundo Prill et al. (2012), isso ocorre pela alta taxa respiratória e produção de etileno que a fruta possui, fator que acelera o amadurecimento, não suportando baixas temperaturas, sendo armazenada na faixa entre $12-13{ }^{\circ} \mathrm{C}$. Entretanto, na literatura científica ainda há pouca informação sobre o comportamento de cultivares de banana plantados no Brasil quanto ao armazenamento em diferentes temperaturas, o que limita a aplicação de técnicas de conservação. Assim, novos testes necessitam ser feitos para o estudo das temperaturas e da qualidade atmosférica para a conservação de bananas dos diferentes grupos genômicos, o que poderia permitir seu transporte a longas distâncias (Oliveira, 2014a; Pereira et al., 2020).

Diante dos aspectos levantados, esta pesquisa teve como objetivo avaliar genótipos da bananeira 'Prata', simulando o armazenamento refrigerado e comercialização.

\section{Metodologia}

\subsection{Colheita e preparo dos frutos}

Utilizou-se bananas dos genótipos Prata Anã, Prata Catarina e Prata Rio. Os frutos colhidos com 14 semanas de cultivo (aproximadamente 4 meses) foram cedidos pela Empresa Frutacor, localizada no Distrito de Irrigação Jaguaribe-Apodi (DIJA), no município de Limoeiro do Norte (CE).

Os cachos de bananas foram colhidos manualmente nas primeiras horas da manhã, no estádio de maturação 1 (totalmente verde), em novembro de 2016. Após a colheita, os cachos foram despencados em um tanque de $8.000 \mathrm{~L}$ de água com $500 \mathrm{~mL}$ de detergente neutro (para conter o látex, evitando queimar as bananas), uniformizados em buquês com três frutos, acondicionados em caixas de papelão e transportados para o Laboratório de Processamento de Frutas e Hortaliças do Instituto Federal de Educação, Ciência e Tecnologia do Ceará, Campus Limoeiro do Norte (CE).

As bananas dos genótipos Prata Anã, Prata Catarina e Prata Rio foram acondicionadas em bandejas de isopor contendo três frutos e armazenadas em câmara fria durante 23 dias, sendo 15 dias na temperatura de exportação das bananas Prata ( $13 \pm 4{ }^{\circ} \mathrm{C}$ e $85 \pm 4 \%$ U.R.) seguido de 8 dias $\left(22 \pm 4{ }^{\circ} \mathrm{C}\right.$ e $85 \pm 4 \%$ U.R.), simulando-se o período de comercialização.

\subsection{Características avaliadas}

Os frutos de bananeira pertencentes aos genótipos (Prata Anã, Prata Catarina e Prata Rio) foram avaliados no dia da colheita e a cada cinco dias de armazenamento (nos três primeiros tempos) e a cada dois dias (nos quatro últimos tempos) de armazenamento quanto as características físicas e físico-químicas, com análises realizadas no Laboratório de Química de Alimentos do Instituto Federal de Educação, Ciência e Tecnologia do Ceará, Campus Limoeiro do Norte (CE), conforme descritas a seguir:

\subsubsection{Características físicas}

A cada tempo de armazenamento foram avaliadas as características físicas e físico-químicas. As análises físicas foram:

- Perda de massa: medida por meio de balança semi-analítica (Marte-BL3200H) e obtida através da diferença entre a massa inicial dos frutos e aquela obtida em cada período de amostragem, com os resultados expressos em porcentagem (\%); 
- Cor da casca: avaliada a partir de uma escala subjetiva utilizando-se as Normas de Classificação de Banana (Pbmh; Pif, 2006);

- Aparência externa: realizada por três avaliadores, utilizando-se uma escala visual e subjetiva variando de 5 a 1 , de acordo com a intensidade de depressões, murcha, ataque fúngico e manchas escuras na superfície do fruto, em que: $5=$ ausência de manchas, murcha, depressões ou ataque fúngico; 4 = leve (1-10\% afetado); 3 = moderado (11-30\% afetado); $2=$ severo (31-50\% afetado) e $1=$ fruto extremamente deteriorado (acima de $50 \%$ da parte do fruto afetada). Frutos com nota inferior a 3,0 foram considerados impróprios para a comercialização;

- Firmeza da polpa: determinada pela resistência à penetração, utilizando-se penetrômetro manual (McCormickFT327), com valor máximo de leitura $29 \mathrm{lb} / \mathrm{pol}^{2}$ (libras por polegadas ao quadrado) e ponteira cilíndrica de $8 \mathrm{~mm}$ de diâmetro. Foram realizadas duas leituras por fruto na região mediana, equatorial e equidistante. $\mathrm{O}$ resultado foi obtido em $\mathrm{lb} / \mathrm{pol}^{2}$ e convertido em Newtons (N), através da multiplicação pelo fator 4,448;

- Espessura da casca e diâmetro da polpa: as medidas foram realizadas com uso de um paquímetro (SteinmeyerFMS). Para espessura da casca foram feitas duas medidas por fruto (lados opostos) e o diâmetro da polpa foi realizado na região mediana do fruto. Os resultados foram expressos em $\mathrm{mm}$;

\subsubsection{Características físico-químicas}

- $p H$ : determinado diretamente na polpa, utilizando-se um potenciômetro digital (HANNA-21), conforme IAL (2008);

- Acidez titulável: determinada através da titulação volumétrica, por meio da diluição de $5 \mathrm{~g}$ de polpa em $50 \mathrm{~mL}$ de água destilada, titulando com solução de $\mathrm{NaOH}(0,1 \mathrm{~N})$, usando o indicador fenolftaleína a $1 \%$. Os resultados foram expres sos em porcentagem de ácido málico (IAL, 2008);

- Sólidos solúveis: medido por leitura em refratômetro digital (Abbe Refractometer, Optronics-WYA-1S) com compensação automática de temperatura sendo os resultados expressos em ${ }^{\circ}$ Brix (AOAC, 2002);

- SS/AT: determinada pelo quociente entre os valores de sólidos solúveis e acidez titulável. Os resultados foram expressos em número puro;

- Açúcares solúveis totais: determinados pelo método da Antrona conforme Yemn e Willis (1954). As leituras foram feitas em espectrofotômetro (FEMTO-600Plus) a $620 \mathrm{~nm}$ e os resultados expressos em porcentagem de glicose.

\subsection{Delineamento Experimental}

O delineamento experimental utilizado foi o inteiramente casualizado em esquema fatorial 3 x 8 , com três repetições de três frutos por parcela, totalizando 216 frutos avaliados, sendo 72 frutos de cada genótipo. O primeiro fator constou dos genótipos (Prata Anã, Prata Catarina e Prata Rio) e o segundo dos tempos de armazenamento (0, 5, 10, 15, 17, 19, 21 e 23) dias. 


\subsubsection{Análise estatística}

Para análise dos dados, utilizou-se estatística descritiva por meio de comparação de médias dos tratamentos, seguidos pelo desvio padrão proveniente de 3 repetições de 3 frutos por parcela.

\section{Resultados e Discussão}

\subsection{Características físicas}

- Perda de massa

Verificou-se aumento para todos os genótipos estudados (Figura 1A). No $21^{\circ}$ dia de armazenamento, observou-se maior perda de massa nas frutas do genótipo Prata Rio seguida pela Prata Anã e menor perda de massa para as do genótipo Prata Catarina, com médias de 6,31; 6,29 e 5,42\%, respectivamente.

A perda de massa em frutos é oriunda principalmente da perda de água ocasionada pela respiração e transpiração (Palharini et al., 2016; Souza et al., 2019).

Comportamento semelhante foi observado por Sarmento et al. (2015b), quando avaliaram a qualidade pós-colheita da banana 'Prata Catarina' submetida a diferentes danos mecânicos e armazenamento refrigerado, verificando-se perda de massa de 7,33\% para os frutos do tratamento controle no $21^{\circ}$ dia de armazenamento à temperatura de $14{ }^{\circ} \mathrm{C}$. Ainda estudando a qualidade pós-colheita de banana 'Prata Rio' refrigerada, Santos (2017) observou perda de massa de 9,37\% no $30^{\circ}$ dia de armazenamento à temperatura de $13{ }^{\circ} \mathrm{C}$.

Figura 1 - Perda de massa (A) e cor da casca (B) de frutos da bananeira dos genótipos Prata Anã, Prata Catarina e Prata Rio armazenados a temperatura refrigerada por 15 dias a $13 \pm 4{ }^{\circ} \mathrm{C}\left(85 \pm 4 \%\right.$ U.R.) seguido de 8 dias a $22 \pm 4{ }^{\circ} \mathrm{C}(85 \pm 4 \%$ U.R.). A linha vertical indica o início da simulação da comercialização.
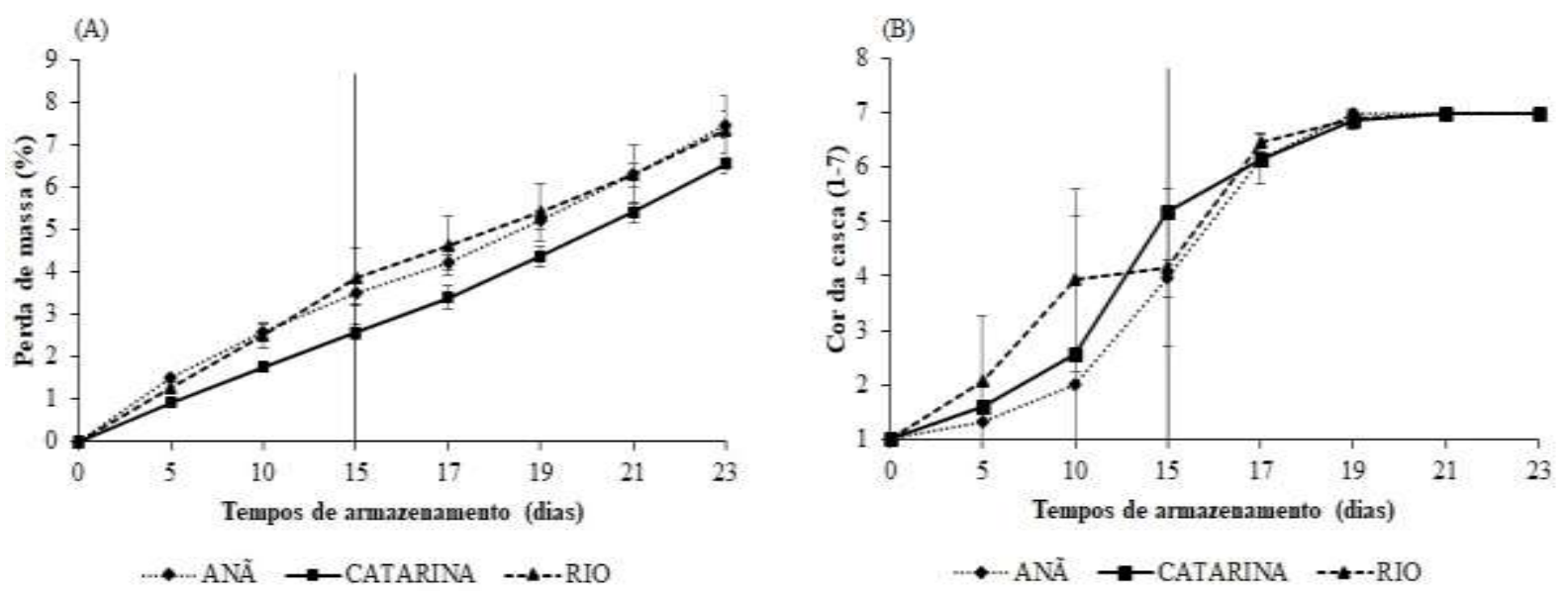

Fonte: Dados da pesquisa, Limoeiro do Norte (CE) (2017).

Verificou-se alteração da coloração da casca dos frutos durante o armazenamento (Figura 1B). Inicialmente, os frutos dos genótipos Prata Anã, Prata Catarina e Prata Rio apresentaram grau de coloração 1,0 (totalmente verde) e ao $21^{\circ}$ dia de armazenamento grau de coloração 7,0 (amarelo com áreas marrons). Observou-se também que durante o armazenamento a $13{ }^{\circ} \mathrm{C}$ os frutos do genótipo Prata Rio anteciparam o amarelecimento da casca em relação aos demais genótipos.

A mudança de cor da casca do estádio de cor 1 (casca totalmente verde) para 6 (casca totalmente amarela) observada na Figura 2, é caracterizada pelo decréscimo dos teores de clorofila, o que evidencia o aparecimento da coloração amarela (Aquino et al., 2016; Silva Campelo et al., 2020). 
Figura 2 - Escala de maturação de frutos da bananeira dos genótipos Prata Anã, Prata Catarina e Prata Rio durante 23 dias de armazenamento a temperatura refrigerada por 15 dias a $13 \pm 4{ }^{\circ} \mathrm{C}\left(85 \pm 4 \%\right.$ U.R.) seguido de 8 dias a $22 \pm 4{ }^{\circ} \mathrm{C}(85 \pm 4 \%$ U.R.). IFCE, Limoeiro do Norte (CE), 2017.
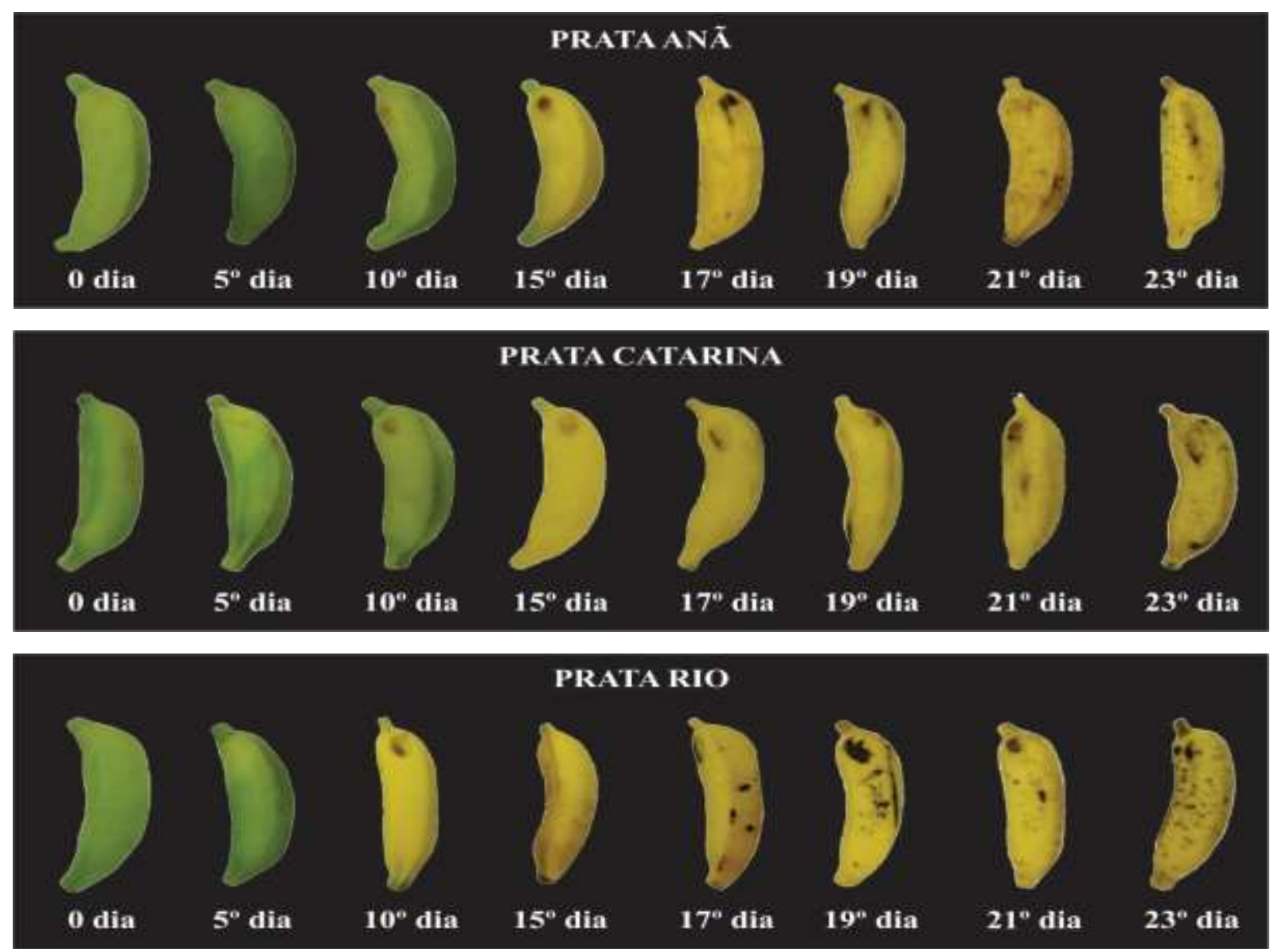

Fonte: Dados da pesquisa, Limoeiro do Norte (CE) (2017).

O mesmo comportamento da evolução do índice de cor da casca dos frutos de bananeira durante o amadurecimento, foi observado por Santos (2017) que, avaliando a qualidade pós-colheita de banana 'Prata Rio' refrigerada, verificou-se que os frutos apresentaram grau de coloração 7,0 no $25^{\circ}$ dia de armazenamento à temperatura de $13{ }^{\circ} \mathrm{C}$.

Observou-se a redução das notas atribuídas à aparência externa (Figura (3A) e firmeza da polpa (Figura (3B) em todos os genótipos estudados durante o período de armazenamento. No $21^{\circ}$ dia de armazenamento os frutos dos genótipos Prata Anã, Prata Catarina e Prata Rio apresentaram notas 2,70; 3,01 e 1,63, respectivamente, tendo os frutos do genótipo Prata Catarina obtido melhores valores para a aparência externa. 
Figura 3 - Aparência externa (A) e firmeza da polpa (B) de frutos da bananeira dos genótipos Prata Anã, Prata Catarina e Prata Rio armazenados a temperatura refrigerada por 15 dias a $13 \pm 4{ }^{\circ} \mathrm{C}\left(85 \pm 4 \%\right.$ U.R.) seguido de 8 dias a $22 \pm 4{ }^{\circ} \mathrm{C}(85 \pm$ $4 \%$ U.R.). A linha vertical indica o início da simulação da comercialização. A linha horizontal pontilhada representa o limite para comercialização (A).
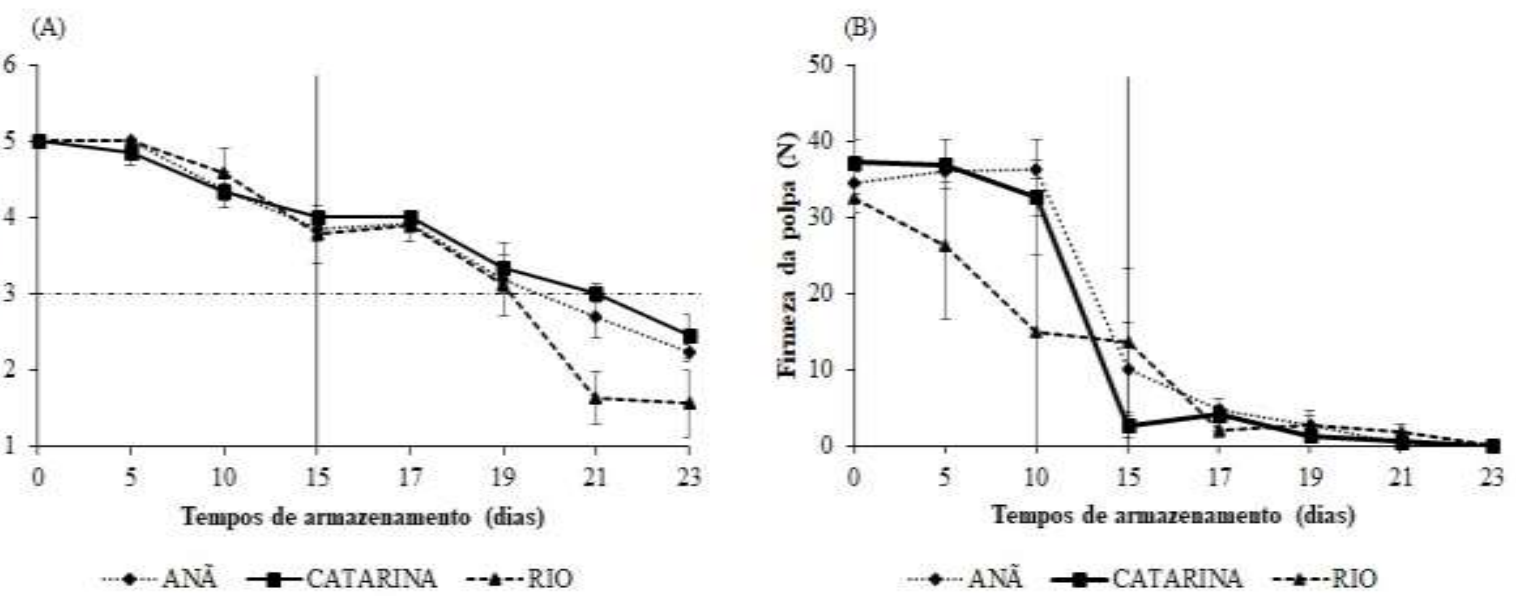

Fonte: Dados da pesquisa, Limoeiro do Norte (CE) (2017).

Conforme a escala utilizada para avaliar esta variável, os frutos que apresentaram notas inferiores a 3,0 foram considerados impróprios para a comercialização. Dessa forma, observou-se que a vida útil pós-colheita dos frutos dos genótipos Prata Anã e Prata Rio foi de 19 dias e dos frutos do genótipo Prata Catarina foi de 21 dias. As principais alterações que levaram à redução nas notas foram murchamento e escurecimento da casca, sendo este último mais visível nos frutos do genótipo Prata Rio.

A aparência externa é uma variável de importância em frutos, pois ela define a intenção de compra pelo consumidor. Se a mesma for afetada haverá redução na qualidade dos frutos e na aceitabilidade, mas apesar disso nem sempre um fruto aparentemente saudável tem melhor sabor e aroma (Beserra, 2015; Mendonça et al., 2004).

O comportamento de resposta à aparência externa foi, ainda, observado por Fernandes (2012) que, avaliando frutos de cinco cultivares de bananeiras em Baraúna-RN, verificou nota média de 1,77 para a aparência externa da cultivar Prata Catarina no $12^{\circ}$ dia de armazenamento, à temperatura de $24^{\circ} \mathrm{C}$.

Durante o período de armazenamento, os valores de firmeza da polpa dos frutos reduziram significativamente, na medida que avançaram sua maturação (Figura 3B). Ao $21^{\circ}$ dia de armazenamento verificou-se valores de firmeza da polpa de 0,25; 0,49 e 1,73 N para os frutos dos genótipos Prata Anã, Prata Catarina e Prata Rio, respectivamente.

Observou- se ainda que os frutos do genótipo Prata Rio tiveram perda mais acelerada da firmeza da polpa durante o armazenamento a $13{ }^{\circ} \mathrm{C}$, comportamento esse associado à mudança de cor (Figura 1B).

A perda de firmeza durante o amadurecimento dos frutos é ocasionada pela degradação da parede celular, perda de umidade e, em frutas como banana e manga, pela degradação do amido (Sarmento et al., 2015a; Barros et al., 2020).

Os resultados de firmeza da polpa mostraram comportamento semelhante aos verificados por Santos et al. (2017), quando avaliaram a conservação de banana 'Prata Anã' a 12 e $14{ }^{\circ} \mathrm{C}$ sob atmosfera controlada, observando-se firmeza da polpa de 6,83 e $2,45 \mathrm{~N}$, respectivamente, no $35^{\circ}$ dia de armazenamento.

Para a variável espessura da casca, verificou-se declínio dos valores durante o período de armazenamento para os genótipos estudados (Figura 4A). Ao $21^{\circ}$ dia de armazenamento, os frutos dos genótipos Prata Anã, Prata Catarina e Prata Rio apresentaram valores de 3,55; 3,90 e 3,58 mm, respectivamente. 
Figura 4 - Espessura da casca (A) e diâmetro da polpa (B) de frutos da bananeira dos genótipos Prata Anã, Prata Catarina e Prata Rio armazenados a temperatura refrigerada por 15 dias a $13 \pm 4{ }^{\circ} \mathrm{C}\left(85 \pm 4 \%\right.$ U.R.) seguido de 8 dias a $22 \pm 4{ }^{\circ} \mathrm{C}(85 \pm$ $4 \%$ U.R.). A linha vertical indica o início da simulação da comercialização.
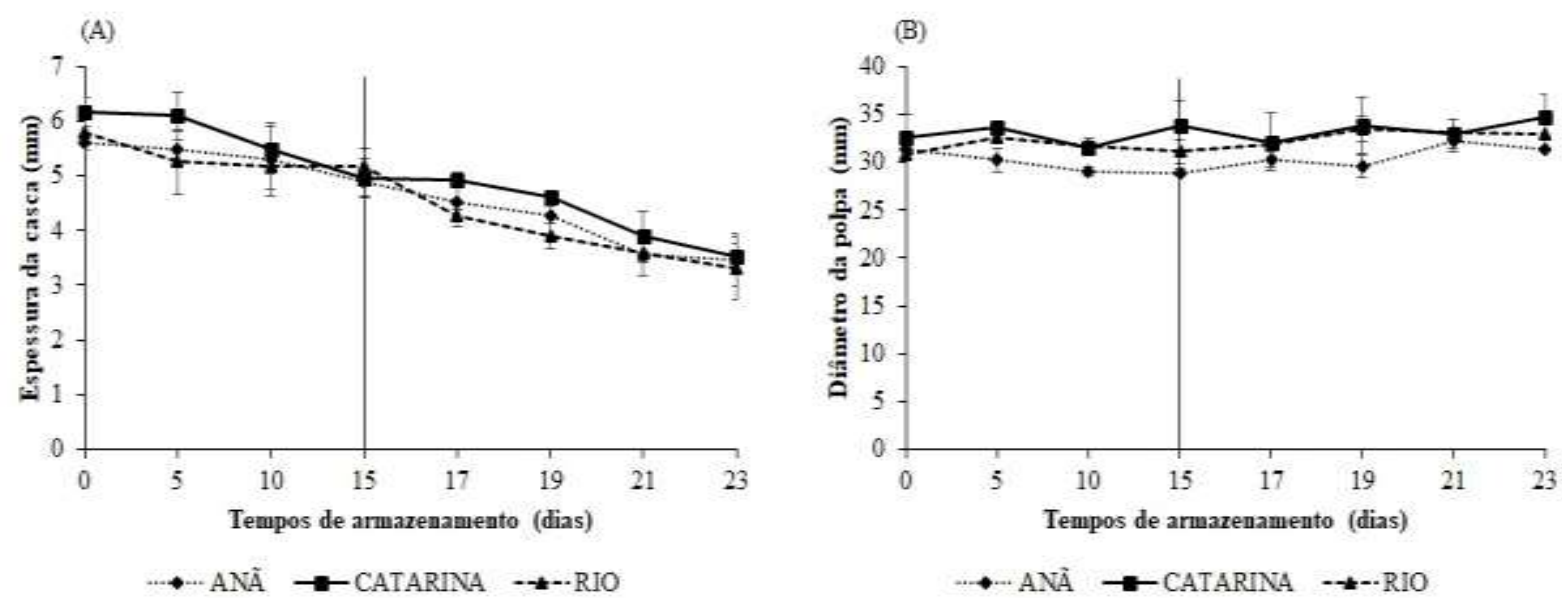

Fonte: Dados da pesquisa, Limoeiro do Norte (CE) (2017).

Observou-se que praticamente não houve alteração nos valores do diâmetro da polpa durante o período de armazenamento para os genótipos estudados (Figura 4B). Ao $21^{\circ}$ dia de armazenamento, os frutos dos genótipos Prata Anã, Prata Catarina e Prata Rio apresentaram valores de 32,20; 33,02 e 33,14 mm, respectivamente.

Segundo Matias (2009), a casca reduz a sua espessura com o amadurecimento do fruto, tanto pela desidratação, possivelmente devido a um fluxo de água para a polpa, decorrente da redução do seu potencial osmótico associado à hidrólise do amido, bem como pela transpiração, devido ao gradiente de pressão de vapor d'água entre a casca e o ambiente adjacente (Santos et al., 2019).

Comportamento semelhante foi observado por Ramalho Neta et al. (2014), em estudo da caracterização física de diferentes cultivares de bananeira provenientes da Chapada do Apodi, verificando-se espessura da casca de 3,47 e 3,38 mm para as cultivares Prata Anã e Prata Catarina, respectivamente. Também estudando frutos de cinco cultivares de bananeiras em Baraúna-RN, Fernandes (2012) verificou espessura da casca de 2,48 mm para a cultivar Prata Catarina no $12^{\circ}$ dia de armazenamento, à temperatura de $24^{\circ} \mathrm{C}$.

Resultados semelhantes foram verificados por Ramalho Neta et al. (2014), quando avaliaram características físicas de diferentes cultivares de bananeira provenientes da Chapada do Apodi, observando-se espessura da polpa de 32,23 e 34,00 mm para as cultivares Prata Anã e Prata Catarina, respectivamente.

Avaliando a qualidade pós-colheita de banana da cultivar 'Valery' submetida ao cultivo orgânico e convencional, Sarmento et al. (2012) obtiveram valores de 38,80 e 38,70 mm para o diâmetro dos frutos cultivados pelo método convencional e orgânico, respectivamente, no $36^{\circ}$ dia de armazenamento.

\subsection{Características físico-químicas}

- $\mathrm{pH}$

Para a variável $\mathrm{pH}$, observou-se redução dos valores durante o período de armazenamento para os genótipos estudados (Figura 5A). No $21^{\circ}$ dia de armazenamento, os frutos dos genótipos Prata Anã, Prata Catarina e Prata Rio apresentaram valores de 4,56; 4,63 e 4,89, respectivamente.

As variáveis $\mathrm{pH}$ e acidez titulável apresentaram comportamento inversamente proporcional, pois à medida em que $\mathrm{o}$ valor de $\mathrm{pH}$ diminuiu, a porcentagem de acidez titulável aumentou (Figuras 5A e 5B). 
Figura 5 - pH (A) e acidez titulável (B) de frutos da bananeira dos genótipos Prata Anã, Prata Catarina e Prata Rio armazenados a temperatura refrigerada por 15 dias a $13 \pm 4{ }^{\circ} \mathrm{C}\left(85 \pm 4 \%\right.$ U.R.) seguido de 8 dias a $22 \pm 4{ }^{\circ} \mathrm{C}(85 \pm 4 \%$ U.R.). A linha vertical indica o início da simulação da comercialização.
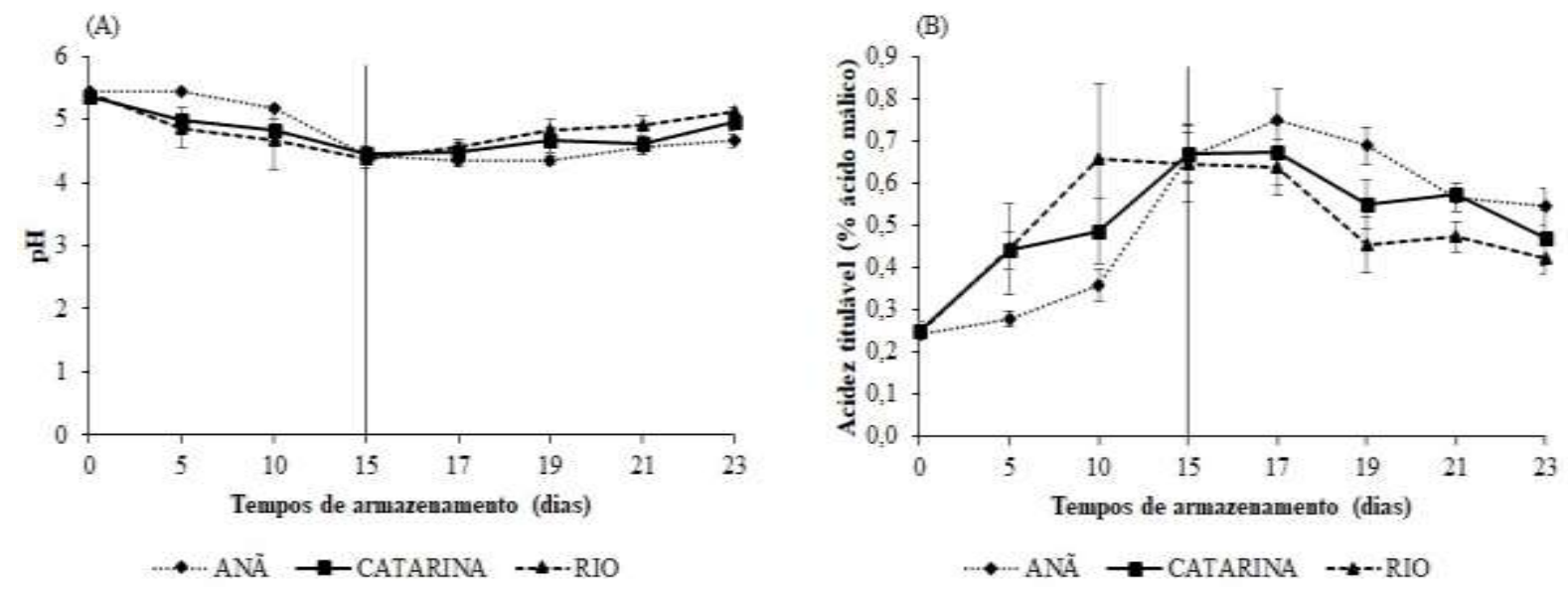

Fonte: Dados da pesquisa, Limoeiro do Norte (CE) (2017).

O comportamento de resposta ao $\mathrm{pH}$ foi, ainda, observado por Martins et al. (2007) que, avaliando o armazenamento refrigerado de banana 'Prata Anã' proveniente de cachos com 16, 18 e 20 semanas, verificaram para esta variável valores de 5,$35 ; 5,22$ e 5,12 , respectivamente, no $35^{\circ}$ dia de armazenamento a $12^{\circ} \mathrm{C}$.

Conforme Chitarra e Chitarra (2005), os valores de pH diminuem após a colheita da banana e aumentam no final do amadurecimento ou início da senescência das frutas.

Avaliando a qualidade pós-colheita de banana 'Prata Anã' armazenada sob diferentes condições, Viviani e Leal (2007) verificaram para a variável pH, valor médio final de 4,15 para os frutos armazenados sob refrigeração.

Comportamento semelhante foi verificado por Jesus et al. (2004), em estudo da caracterização física e química de frutos pertencentes a diferentes genótipos de bananeira, observando-se para a variável pH, valor de 4,44 para o genótipo Prata Anã.

Verificou-se aumento com posterior decréscimo dos teores de acidez titulável durante o período de armazenamento para os genótipos estudados (Figura 5B). Ao $21^{\circ}$ dia de armazenamento os frutos dos genótipos Prata Anã, Prata Catarina e Prata Rio apresentaram teores de 0,57; 0,58 e 0,47\% de ácido málico, respectivamente.

Durante o armazenamento a $13{ }^{\circ} \mathrm{C}$ observou-se, também, que os frutos da 'Prata Rio' apresentaram os maiores teores de acidez titulável, comportamento que corrobora com as alterações de cor e firmeza da polpa verificados durante o armazenamento dos frutos indicando que esse genótipo apresentava-se, possivelmente, com o processo de amadurecimento mais acelerado em relação aos demais genótipos.

Durante a maturação, ocorre um decréscimo acentuado no teor de ácidos orgânicos na maioria dos frutos, uma vez que estão sendo largamente utilizados como substratos no processo respiratório. No entanto, a concentração não declina em todos os frutos durante a maturação, como na banana, na qual há um aumento na concentração de ácido málico (Chitarra; Chitarra, 2005).

Os resultados corroboraram com os valores obtidos por Martins et al. (2007), quando avaliaram o armazenamento refrigerado de banana 'Prata Anã' proveniente de cachos com 16, 18 e 20 semanas, verificando-se teores de acidez titulável de 0,$29 ; 0,34$ e $0,36 \%$, respectivamente, no $35^{\circ}$ dia de armazenamento à temperatura de $12^{\circ} \mathrm{C}$. 


\section{- Sólidos solúveis}

Para a variável sólidos solúveis observou-se aumento dos teores para os genótipos estudados (Figura 6A). Ao $21^{\circ}$ dia de armazenamento os frutos dos genótipos Prata Anã, Prata Catarina e Prata Rio apresentaram teores de 25,20; 25,77 e 23,17 ${ }^{\circ}$ Brix, respectivamente, sendo que os frutos do genótipo Prata Catarina apresentaram maior teor de sólidos solúveis. Esse aumento está relacionado à hidrólise do amido e consequente o acúmulo de açúcares solúveis, principalmente a glicose.

Sarmento et al. (2015b) avaliando a qualidade pós-colheita da banana 'Prata Catarina' submetida a diferentes danos mecânicos e armazenamento refrigerado, verificaram valor de sólidos solúveis de $18,87^{\circ}$ Brix para os frutos controle, no $21^{\circ}$ dia de armazenamento sob temperatura de $14^{\circ} \mathrm{C}$.

Avaliando a conservação de banana 'Prata Anã' a 12 e $14^{\circ} \mathrm{C}$ sob atmosfera controlada, Santos et al. (2017) observaram teores de sólidos solúveis inferiores, com médias de 10,47 e $11,05{ }^{\circ}$ Brix nas temperaturas de 12 e $14{ }^{\circ} \mathrm{C}$, respectivamente, no $35^{\circ}$ dia de armazenamento.

Figura 6 - Sólidos solúveis (A) e relação SS/AT (B) de frutos da bananeira dos genótipos Prata Anã, Prata Catarina e Prata Rio armazenados a temperatura refrigerada por 15 dias a $13 \pm 4{ }^{\circ} \mathrm{C}\left(85 \pm 4 \%\right.$ U.R.) seguido de 8 dias a $22 \pm 4{ }^{\circ} \mathrm{C}(85 \pm 4 \%$ U.R.). A linha vertical indica o início da simulação da comercialização.
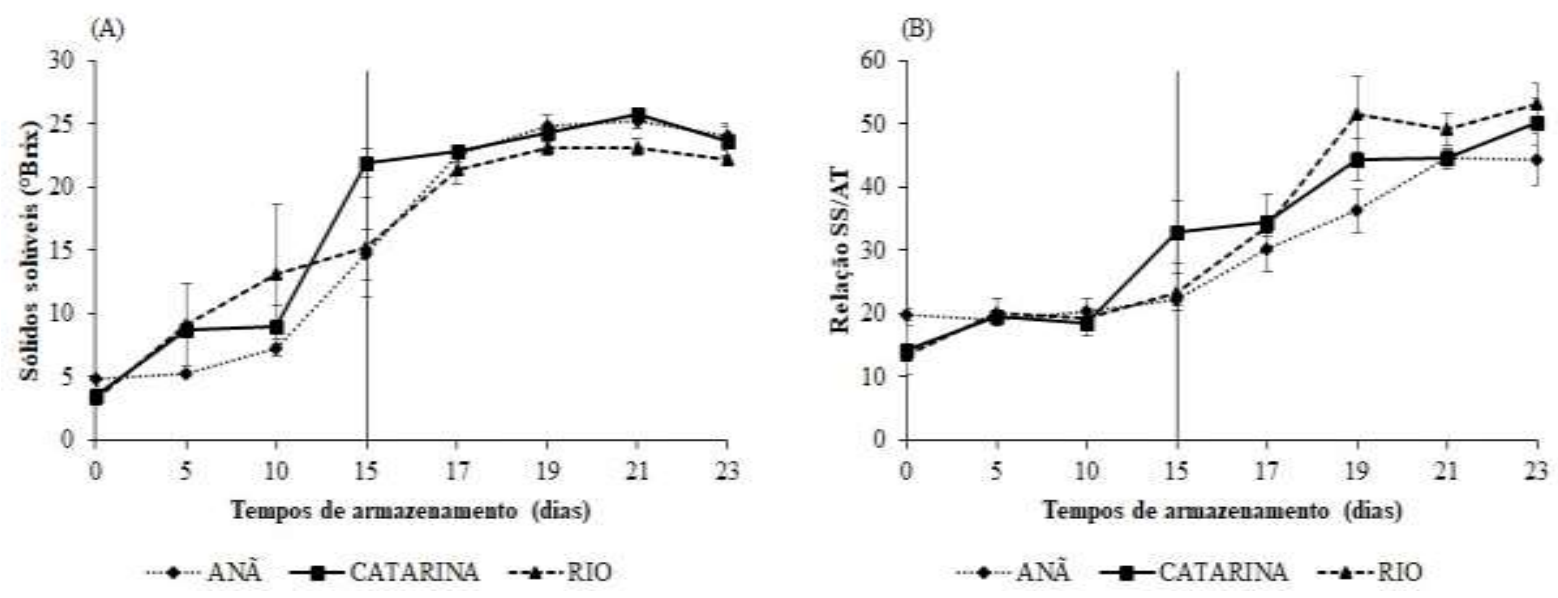

Fonte: Dados da pesquisa, Limoeiro do Norte (CE) (2017).

\section{- SS/AT}

Verificou-se aumento nos valores da relação SS/AT durante o período de armazenamento (Figura 6B). No $21^{\circ}$ dia de armazenamento, registrou-se valores de 44,58; 44,77 e 49,15, para os frutos dos genótipos Prata Anã, Prata Catarina e Prata Rio, respectivamente, sendo que o genótipo Prata Rio apresentou melhores valores para essa variável.

A relação sólidos solúveis/acidez titulável é um índice representativo da medição isolada dos açúcares ou da acidez (Chitarra; Chitarra, 2005). Assim, quanto maior essa relação, maior será a maturação do fruto e melhor seu sabor pelo balanço entre o doce e o ácido (Sanches et al., 2017).

Resultados semelhantes foram observados por Santos (2017) que, avaliando a qualidade pós-colheita de banana 'Prata Rio' refrigerada, verificou que os frutos apresentaram relação SS/AT o valor de 50,3 no $30^{\circ}$ dia de armazenamento à temperatura de $13-{ }^{\circ} \mathrm{C}$.

Avaliando a qualidade pós-colheita da banana 'Prata Catarina' submetida a diferentes danos mecânicos e armazenamento refrigerado, Sarmento et al. (2015b), observaram que a relação SS/AT demonstrou o valor de 42,6 para os frutos do tratamento controle no $21^{\circ}$ dia de armazenamento à temperatura de $14-{ }^{\circ} \mathrm{C}$. 
- Açúcares solúveis totais

Observou-se aumento dos teores de açúcares solúveis totais durante o período de armazenamento para os genótipos estudados (Figura 7). No $21^{\circ}$ dia de armazenamento, os frutos dos genótipos Prata Anã, Prata Catarina e Prata Rio apresentaram teores de 13,$29 ; 13,95$ e $14,58 \%$, respectivamente.

Figura 7 - Açúcares solúveis totais de frutos da bananeira dos genótipos Prata Anã, Prata Catarina e Prata Rio armazenados a temperatura refrigerada por 15 dias a $13 \pm 4{ }^{\circ} \mathrm{C}\left(85 \pm 4 \%\right.$ U.R.) seguido de 8 dias a $22 \pm 4{ }^{\circ} \mathrm{C}(85 \pm 4 \%$ U.R.). A linha vertical indica o início da simulação da comercialização.

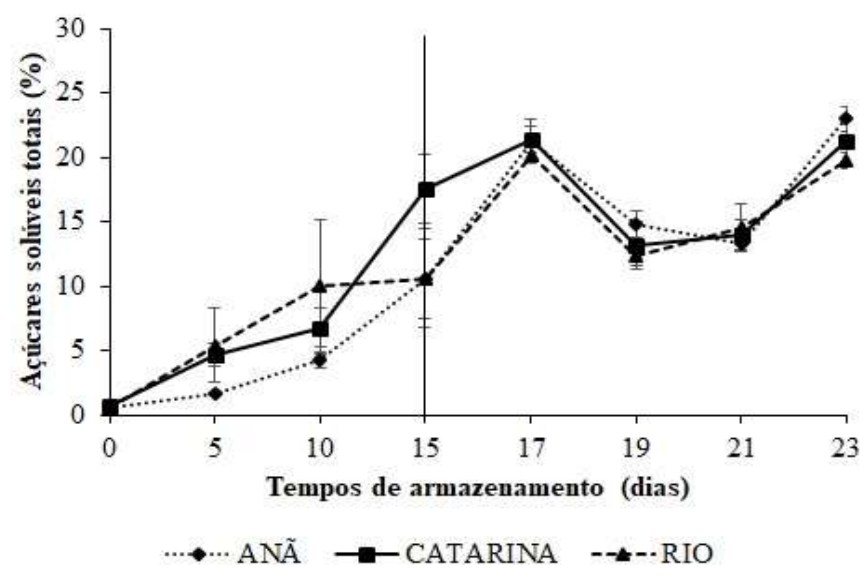

Fonte: Dados da pesquisa, Limoeiro do Norte (CE) (2017).

O aumento do teor de açúcares totais é decorrente da hidrólise do amido que fornece como produto de sua degradação açúcares solúveis como a glicose. O fornecimento destes açúcares influencia diretamente o teor de sólidos solúveis (Figura 6A) da polpa dos frutos, visto que estes em sua maioria são compostos principalmente por açúcares, além de outras substâncias dissolvidas no suco celular como ácidos orgânicos e vitaminas (Oliveira, 2014b; Rocha; Uribe, 2018).

Mota et al. (1997), avaliando a composição em carboidratos de algumas cultivares de banana (Musa spp.) durante o amadurecimento, verificaram comportamento semelhante ao do presente trabalho para as cultivares Nanica e Nanicão, que apresentaram ao final do armazenamento teores de 20,6 e 20,1\% de açúcares solúveis, respectivamente.

Para pesquisas futuras, sugere-se o emprego da refrigeração durante o armazenamento, visando a exportação dos frutos e também simular as temperaturas de comercialização da banana 'Prata' nos países importadores, com o intuito de aprofundar a compreensão da fisiologia, principalmente no que diz respeito ao genótipo Prata Rio, além da utilização de compostos inibidores da ação do etileno, como o 1-metilciclopropeno (1-MCP).

\section{Conclusões}

O genótipo Prata Catarina apresentou menor perda de massa e melhor aparência externa ao $21^{\circ}$ dia de armazenamento. 
Os genótipos Prata Anã e Prata Rio apresentaram metabolismo mais lento e mais acelerado, respectivamente, durante o armazenamento refrigerado a $13{ }^{\circ} \mathrm{C}$, pois apresentaram comportamento diferenciado quanto a cor da casca, firmeza da polpa, acidez titulável, sólidos solúveis e açúcares solúveis totais.

Com base na aparência externa, a vida útil pós-colheita dos frutos dos genótipos Prata Anã e Prata Rio foi de 19 dias $\left(15\right.$ dias a $13{ }^{\circ} \mathrm{C}$ e 4 dias a $\left.22^{\circ} \mathrm{C}\right)$, enquanto que dos frutos do genótipo Prata Catarina foi de 21 dias $\left(15\right.$ dias a $13{ }^{\circ} \mathrm{C}$ e 6 dias a $\left.22^{\circ} \mathrm{C}\right)$.

\section{Agradecimentos}

Ao Instituto Federal de Educação, Ciência e Tecnologia do Ceará (IFCE), Campus Limoeiro do Norte (CE) e à Coordenação de Aperfeiçoamento de Pessoal de Nível Superior (CAPES), pela bolsa concedida.

\section{Referências}

AOAC - Association of Official Analytical Chemistry (2002). Official methods of analysis of the association of official analytical chemistry. AOAC, 1115p.

Aquino, C. F., Salomão, L. C. C., \& Azevedo, A. M. (2016). Qualidade pós-colheita de banana 'Maçã' tratada com ácido giberélico avaliada por redes neurais artificiais. Pesquisa Agropecuária Brasileira, 51(7):824-833.

Araújo, A. K. P., Araújo, R. C., Martins, 1. P., Mousa, M., Mantos, M. F, \& Sousa, A. B. B. Bioactive compounds and carbohydrates in the 'Pacovan' banana subjected to coating with carnaúba wax. Research, Society and Development, 9(11) e87091110391.

Barros, H. E. A., Natarelli, C. V. L., Oliveira, A. L. M., Abreu, D. J. M., Carvalho, E. E. N., \& Boas, E. V. D. B. V. (2020). Alterações dos aspectos físicos e bioquímicos durante o amadurecimento de frutos de cultivares de bananeira (Musa spp.). Research, Society and Development, 9(9) e596997618.

Beserra, H. N. B. R. (2015) influência do tempo de remoção do filme PVC sobre o amadurecimento de atemoia 'Gefner'. Dissertação de Mestrado, Instituto Federal de Educação, Ciência e Tecnologia do Ceará.

Chitarra, M. I. F., \& Chitarra, A. B. (eds) (2005) Pós-colheita de frutas e hortaliças - Fisiologia e manuseio. UFLA.

EMBRAPA - Empresa Brasileira de Pesquisa Agropecuária (2014). Banana. EMBRAPA. http://www. cnpmf.embrapa.br/index.php?p=pesquisaculturas_pesquisadasbanana. php\&menu=.

EMBRAPA - Empresa Brasileira de Pesquisa Agropecuária (2017). Cultivo da banana para o agropólo Jaguaribe-Apodi, Ceará. EMBRAPA. http://sistemasdeproducao.cnptia.embrapa.br.

EMBRAPA - $\quad$ Empresa Brasileira de Pesquisa Agropecuária $\quad$ (2019). Produção Agrícola $\quad$ Municipal. http://www.cnpmf.embrapa.br/Base_de_Dados/index_pdf/dados/brasil/laranja/b1_laranja.pdf.

EMBRAPA - $\quad$ Empresa Brasileira de Pesquisa Agropecuária (2019). Produção Agrícola Municipal.

http://www.cnpmf.embrapa.br/Base_de_Dados/index_pdf/dados/brasil/banana/b1_banana.pd.

Fernandes, P. L. D. O. (2012) avaliação de cinco cultivares de bananeiras em Baraúna/RN. Dissertação de Mestrado, Universidade Federal Rural do SemiÁrido.

IAL - Instituto Adolfo Lutz (2008) Normas analíticas do instituto Adolfo Lutz: métodos físicos e químicos para análise de alimentos. IAL, 1020p.

IBGE - Instituto Brasileiro de Geografia e Estatística (2014) Produção agrícola municipal. IBGE. http://www.ibge.gov.br.

IBGE - Instituto Brasileiro de Geografia e Estatística (2015) Produção agrícola municipal. IBGE. http://www.ibge.gov.br.

Jesus S. C. D., Folegatti M. I. D. S., Matsuura F. C. A. U., \& Cardoso R. L (2004) Caracterização física e química de frutos de diferentes genótipos de bananeira. Bragantia 63(3):315-323.

Lichtemberg L. A., \& Hinz R. H (2010) Atualidades na colheita e pós-colheita da banana. In: Simpósio Brasileiro sobre Bananicultura.

Maia, A. H, Sousa, V. S, \& Sousa M. E. Produtividade de bananeira brs princesa consorciada com adubos verdes em Nova Xavantina, Mato Grosso, Brasil. Brazilian Journal of Development, 5(12) 29772-29785.

Martins, R. N, Dias, M. S. C, Vilas Boas, E. V. D. B., \& Santos, L. O (2007) Armazenamento refrigerado de banana 'Prata Anã' proveniente de cachos com 16, 18 e 20 semanas. Ciência e Agrotecnologia 31(5):1423-1429.

Matias M. D. L. (2009) desenvolvimento de tecnologia para conservação pós-colheita de bananas resistentes à Sigatoka Negra. Dissertação de Mestrado, Universidade Federal do Ceará.

Mendonça, F. V. D. S., Menezes J. B., Gois, V. A. D., Guimarães, A. A., Nunes, G. H. D. S., \& Mendonça Júnior, C. F. D. (2004) Efeito do retardamento da colheita, na qualidade e na vida útil do melão Orange Flesh. Horticultura Brasileira 22(1): 35-38. 
Mota, R. V. D., Lajolo, F. M., \& Cordenunsi, B. R. (1997) Composição em carboidratos de alguns cultivares de banana (Musa spp.) durante o amadurecimento. Ciência e Tecnologia de Alimentos 17(2):94-97.

Oliveira, J. A. A. (2014a) tolerância ao frio dos frutos de diferentes cultivares de bananeiras. Dissertação de Mestrado, Universidade Federal de Viçosa.

Oliveira, Z. L. D. (2014b) armazenamento refrigerado de atemoia 'Gefner’ em atmosfera modificada. Dissertação de Mestrado, Instituto Federal de Educação, Ciência e Tecnologia do Ceará.

Palharini, M. C. D. A., Fischer, I. H., Alves, A. R. D. O. F., Fileti, M. D. S., \& Nogueira Júnior, A. F. (2016) Qualidade de goiabas 'Pedro Sato' em função de tratamentos alternativos em pós-colheita. Revista Brasileira de Fruticultura 38(1):129-140.

PBMH \& PIF - Programa Brasileiro para a Modernização da Horticultura \& Produção Integrada de Frutas (2006) Normas de classificação de banana. PBMH \& PIF, 7p.

Pereira, R. Y. F., Ferreira, M. V. N., Cunha, W. P, Sousa Ramos, D, Sousa, F. B. F., Sousa, S. D. S. N., \& Oliveira, P. S. T. (2020). Perdas pós-colheita de hortifrúti e seus impactos financeiros no varejo do Município de Chapadinha, Maranhão. Research, Society and Development, 9(8), e329985390-e329985390.

Pimentel, R. M. A., Guimarães, F. N., Santos, V. M., \& Resende, J. C. F. (2010) Qualidade pós-colheita dos genótipos de banana PA42-44 e Prata-Anã cultivados no norte de Minas Gerais. Revista Brasileira de Fruticultura 32(2):407-413.

Prill, M. A. D. S., Neves, L. C., Tosin, J. M., \& Chagas, E. A. (2012) Atmosfera modificada e controle de etileno para bananas 'Prata-Anã' cultivadas na Amazônia Setentrional Brasileira. Revista Brasileira de Fruticultura, 34(4):990-1003.

Ramalho Neta, T.., Arrais, I G, Fernandes, P. L. D. O., Silva, D. J., \& Sarmento, J. D. A. (2014) Caracterização física de diferentes cultivares de bananeira provenientes da Chapada do Apodi. In: Feira Internacional de Fruticultura Irrigada - EXPOFRUIT.

Rocha, K R, \& Uribe, S. J (2018). Relação amido e açúcares solúveis durante o processo de maturação da banana 'prata'. Tecnologia e ciências agropecuárias, 122(2):51-56.

Rosa, G. G, Zanandrea, I, Mayer, N. A, \& Bianchi, V J (2017) Effect of genotype on rooting and acclimatization of semihardwood cutting of peach rootstocks. Journal of Agroveterinary Sciences, 16(4) 449-455.

Sanches, A. G, Silva, M. B. D, Moreira, E. G. S, \& Cordeiro, C. A .M (2017) Fontes de amido e temperatura de armazenamento na manutenção da qualidade pós-colheita da pitaya de polpa vermelha. Colloquium Agrariae 13(2):41-54

Santos, D. V. D (2017) Qualidade pós-colheita de banana 'Prata Rio' refrigerada. Monografia de Graduação, Instituto Federal de Educação, Ciência e Tecnologia do Ceará.

Santos, K. F. T., Colnagi, M. L. G. T., Cella, D, \& Spada, R. K. (2018) Fruticultura: estudo do comércio internacional do mamão. Revista Interface Tecnológica, 15(2) 323-335.

Santos, L. O., Martins, R N, Castricini, A, Rodrigues, M. G. V., \& Dias, M. S. C. (2017) 'Prata-Anã' banana conservation at $12{ }^{\circ} \mathrm{C}$ and $14{ }^{\circ} \mathrm{C}$ under controlled atmosphere. Científica 45(1): 57-63.

Santos, W. W. V., Oliveira Silva, K. R., Barbosa, R. C., Oliveira, J. B., Silva, J. S. A., \& Medeiros, E. V. (2019). Efeito de diferentes métodos de maturação sobre a qualidade da banana prata. Diversitas Journal, 4(3), 1092-1104.

Sarmento, D. H. A., Souza. P. A. D., Sarmento, J. D. A., Freitas, R. V. D. S., \& Silva, M. S. (2015a) Armazenamento de banana 'Prata Catarina' sob temperatura ambiente recobertas com fécula de mandioca e PVC. Revista Caatinga 28(2):235-241.

Sarmento, J. D. A., Morais, P. L. D. D., Almeida, M. L. B., Silva, G. G. D., Sarmento, D. H. A., \& Batalha, S. D. A. (2012) Qualidade pós-colheita de banana submetida ao cultivo orgânico e convencional. Revista Brasileira de Produtos Agroindustriais 14(1):85-93.

Sarmento, J. D. A., Morais, P. L. D. D., Almeida, M. L. B., Silva, G. G. D., Rocha, R. H. C., \& Miranda, M. R. A. D. (2015b) Qualidade pós-colheita da banana 'Prata Catarina' submetida a diferentes danos mecânicos e armazenamento refrigerado. Ciência Rural, 45(11):1946-1952.

Silva Campelo, M. E, Silva Morais, A. C, Silva, J. F., Sousa, A. M. C., \& de Souza, J. W. N. (2020) Caracterização e aceitação sensorial de banana prata (Musa paradisiaca) produzida em sistemas orgânico e convencional. Brazilian Journal of Development, 6(9): 65623-65640.

Sousa, S. G., Alencar, G. S. S., \& Alencar, F. H. H. (2017). Análise socioambiental da produção de banana no município de Cariús (CE), Brasil. Ciência E Sustentabilidade, 3(2), 119-144.

Santos Souza, D. V., Souza, P. A., Sousa, P. R. R., Batista, E. M., Costa, F. B., \& Morais, P. L. D. (2019). Pós-colheita de bananas 'Prata Rio' sob armazenamento refrigerado. Revista Verde de Agroecologia e Desenvolvimento Sustentável, 14(2), 343-348.

Viviani, L., \& Leal, P. M. (2007) Qualidade pós-colheita de banana Prata Anã armazenada sob diferentes condições. Revista Brasileira de Fruticultura, 29(3):465-470.

Yemn, E. W., \& Willis, A. J. (1954) The estimation of carbohydrates in plant extracts by anthrone. The Biochemical Journal 57(3):508-514. 